\title{
Characteristics of chronic obstructive pulmonary disease in Spain from a gender perspective
} Pilar Carrasco-Garrido1, Javier de Miguel-Díez*2, Javier Rejas-Gutierrez ${ }^{3}$, Antonio Martín-Centeno ${ }^{4}$, Elena Gobartt-Vázquez ${ }^{5}$, Valentin HernandezBarrera ${ }^{1}$, Angel Gil de Miguel $^{1}$ and Rodrigo Jimenez-Garcia ${ }^{1}$

\begin{abstract}
Address: ${ }^{1}$ School of Health Sciences, Universidad Rey Juan Carlos, Alcorcón (Madrid), Spain, ${ }^{2}$ Department of Pneumology, Hospital General Universitario Gregorio Marañón, Madrid, Spain, ${ }^{3}$ Department of Health Outcomes Research, Medical Unit, Pfizer España, Alcobendas (Madrid), Spain, ${ }^{4}$ Medical Unit, Pfizer España, Alcobendas (Madrid), Spain and ${ }^{5}$ Medical Department, Boehringer Ingelheim España, San Cugat del Vallés (Barcelona), Spain

Email: Pilar Carrasco-Garrido - pilar.carrasco@urjc.es; Javier de Miguel-Díez* - jmiguel.hgugm@salud.madrid.org; Javier RejasGutierrez - Javier.Rejas@pfizer.com; Antonio Martín-Centeno - antonio.martin@pfizer.com; Elena Gobartt-

Vázquez - antonio.martin@pfizer.com; Valentin Hernandez-Barrera - valentin.hernandez@urjc.es; Angel Gil de Miguel - angel.gil@urjc.es; Rodrigo Jimenez-Garcia - rodrigo.jimenez@urjc.es

* Corresponding author
\end{abstract}

Published: 2 January 2009

BMC Pulmonary Medicine 2009, 9:2 doi:10.1 186/1471-2466-9-2
Received: 8 June 2008

Accepted: 2 January 2009

This article is available from: http://www.biomedcentral.com/I47/-2466/9/2

(c) 2009 Carrasco-Garrido et al; licensee BioMed Central Ltd.

This is an Open Access article distributed under the terms of the Creative Commons Attribution License (http://creativecommons.org/licenses/by/2.0), which permits unrestricted use, distribution, and reproduction in any medium, provided the original work is properly cited.

\begin{abstract}
Background: The objective of this study was to analyze the clinical and management characteristics of chronic obstructive pulmonary disease (COPD) in men and women, to determine possible gender-associated differences between the two groups of patients.

Methods: An observational and descriptive epidemiological study (EPIDEPOC study). The study included patients with stable COPD and aged $\geq 40$ years, evaluated in primary care. Data were collected relating to sociodemographic variables, clinical characteristics, quality of life (SF-I2), severity of disease and treatment. The results obtained in men and women were compared.
\end{abstract}

Results: A total of 10,7 II patients $(75.6 \%$ males and $24.4 \%$ females) were evaluated. Significant differences were found between males and females in relation to the following parameters: age $(67.4 \pm 9.2$ years in men vs $66.1 \pm 10.8$ in women, $p<0.05)$, smoking $(91.9 \%$ of the men were smokers or ex-smokers vs $30 \%$ of the women), comorbidity (the frequency of hypertension, diabetes, anxiety and depression was greater in women, while ischemic heart disease was more common in men), mental component of quality of life $(49.4 \pm 10.3$ in men vs $44.6 \pm 11.9$ in women, $p<0.05)$ and severity of disease $(56.5 \pm 13.3 \%$ in men vs $60.7 \pm 3.2$ in women, $p<0.05)$. As regards treatment, the percentage use of long-acting $b_{2}$-adrenergic agonists, anticholinergic agents, theophyllines and mucolytic agents was significant greater in men. The total annual cost of COPD was greater in males than in females $(1989.20 \pm 2364.47 € v s$ I724.53 $\pm 2106.90, p<0.05)$.

Conclusion: The women with COPD evaluated in this study were younger, smoked less and have more comorbidity, a poorer quality of life, and lesser disease severity than men with COPD. However, they generated a lesser total annual cost of COPD than men. 


\section{Background}

In recent years there has been an increase in the incidence, prevalence and mortality of chronic obstructive pulmonary disease (COPD) in women $[1,2]$. Indeed, in some countries such as the United States, Canada, the United Kingdom or Finland, the absolute number of cases of the disease, as well as the number of hospital admissions and deaths, has been greater in women than in men [1,3-5]. This situation has developed despite the fact that classically COPD has been less probably diagnosed in women than in men $[6,7]$.

Recent evidences have found that males and females might show a fenotipically different respond to tobacco smoke, showing men more propensities to develop an emphysema profile of the disease, while women could show mainly more airway affectation. However, as COPD is an inflammatory condition, a sexual dimorphism could be responsible for the different immunological response observed in the human being according to gender [8].

A recent study has shown that among patients with stable COPD, the women smoke less, are comparatively younger, and have less comorbidity than men with the same degree of airways obstruction [9]. However, the mentioned study has some limitations. Firstly, the patients were recruited exclusively from pneumology clinics, and thus possibly were not representative of the overall COPD population. Secondly, the female data could be applied only to those cases of smoking-related COPD, and not to those attributable to exposure to risk factors other than smoking. Third, since women have greater bronchial hyper-responsiveness than men [10], the exclusion of patients with symptoms of asthma or with a positive bronchodilator response may have introduced bias in the population.

The present study was made to evaluate the existence of gender differences in the clinical expression, diagnosis and management of COPD in a non-selected population of patients with the disease, recruited in the primary care setting.

\section{Methods}

\section{Study design and population}

This study forms part of the EPIDEPOC survey, an observational and descriptive, multicenter epidemiological study conducted in the primary care setting to explore the use of health care resources and assess the quality of life of patients with stable COPD [11].

Patient recruitment and calculation of the sample size corresponded to that conducted in the EPIDEPOC study. For calculation of sample size, a cluster design was used, considering 3 types of variables: health centers, physicians, and medical records. As the health centers were considered to be homogeneous and representatives of the Spanish geographical population, the medical record was chosen as the unit of study and the prescriber as the cluster. A previous study in a large cohort of 1,510 primary care patients found that the average annual cost per patient varied widely, with an estimated standard deviation of 3,407 [6]. Assuming a precision of 90, 5,505 medical records needed to be evaluated. If the effect of the cluster design is also taken into account, i.e., the loss of efficacy from the use of clusters, assuming a correlation of 0.3 and a cluster size of 5, a total of 2,422 prescribers and 12,111 medical records would be required. The subjects were consecutively included by primary care physicians in all the Spanish Autonomous Communities, with a distribution proportional to the population in each Community. The patients were recruited during a period of three months (from January 1 to March 31, 2003).

The study included patients of either sex or aged over 40 years, with a diagnosis of COPD established at least 12 months before the start of the study. The diagnosis of COPD was based on the criteria of the Spanish Society of Pneumology and Chest Surgery (Sociedad Española de Neumología y Cirugía Torácica, SEPAR) according to the forced spirometric demonstration of a forced expiratory volume in one second $\left(\mathrm{FEV}_{1}\right)$ of less than $80 \%$ the corresponding reference value, and a $\mathrm{FEV}_{1} /$ forced vital capacity (FVC) ratio of under 0.7 following bronchodilator testing. The severity of COPD was classified into three groups according to the $\mathrm{FEV}_{1}$ : mild $\left(\mathrm{FEV}_{1}: 60-80 \%\right.$ of the reference value), moderate $\left(\mathrm{FEV}_{1}: 40-59 \%\right.$ of the reference value), and severe $\left(\mathrm{FEV}_{1}\right.$ : less than $40 \%$ of the reference value), based on the criteria of the SEPAR [12].

Patients with neurological or psychiatric disease not allowing adequate evaluation at the time of the study were excluded. Patients with COPD exacerbation in the previous month were likewise excluded. Exacerbation was defined as worsening of the clinical condition of the patient, in the form of increased expectoration, purulent sputum production, increased baseline dyspnea, or any combination of these symptoms.

The study was approved by the ethics committee of the Fundación Hospital Alcorcón, and verbal informed consent was obtained in all cases.

\section{Evaluation of the patients}

A single visit was made, in all cases documenting the sociodemographic parameters (including gender), the year of diagnosis of COPD, the severity of the disease, and the use of health care resources in the previous 12 months. Associated comorbidity was also recorded, including the presence or absence of diabetes mellitus. The SF-12 quality of 
life questionnaire (an abridged 12-item version of the SF36) was administered to all patients [13]. These 12 items explain more than $90 \%$ of the variance of the physical and mental components of the SF-36. They can be applied to calculate two scores: physical (PCS-12) and mental (MCS12 ), using a value of 50 with a standard deviation (SD) of 10 as reference population. The SF-12 scores from 0 to 100 , where the higher the score, the better the patient health condition.

The direct costs were calculated from the information relating to the different procedures, supplied by the management authorities of Area 8 Health Care (Madrid) and of the Alcorcón and Móstoles Hospitals. The "human capital" method was used to compute the indirect costs. This method uses as basic hypothesis the equivalence between the value of lost production and the wage associated with such production. In other words, one day off work implies a production loss equivalent to the wage corresponding to that same day. The data on employment and wages was obtained from the Spanish National Statistical Institute (Instituto Nacional de Estadística, INE) [14].

\section{Statistical particulars}

The SPSS version 12.0 statistical package for Microsoft Windows was used throughout. Qualitative variables are given as frequencies and percentages, and quantitative variables as mean, standard deviation, minimum and maximum values. The Pearson $\chi^{2}$ test was used to analyze the relationship between qualitative variables. Normality (Kolmogorov-Smirnov test), has been evaluated for all the quantitative variables. If the variables did fit the normality the Student t-test or ANOVA test for independent measures was used to calculate the differences between the means of two or more groups in the bi-variant analysis. If the normality could not be assumed nonparametric meth- ods (Mann-Whitney $U$ test or Kruskal-Wallism test) were used.

Finally in order to control the confounding effect of covariables all comparisons between males and females have been conducted using multivariate models (logistic regression for binary variables and multiple lineal regression models for continuous variables). In all such cases age and severity of were included as possible confounders. Unfortunately the information about the physician who collected the 5 patients was not included in the database. Therefore we could not analyse the data using logistic regression with random effects. Statistical significance was accepted for $\mathrm{p}<0.05$.

\section{Results}

A total of 10,711 patients $(75.6 \%$ males and $24.4 \%$ females) were evaluated. The mean age was $67.1 \pm 9.66$ years, and was significantly greater in the male subgroup than among the women $(67.40 \pm 9.20$ vs $66.13 \pm 10.82$, p $<0.05$ ). Statistically significant differences were also seen between males and females as refers to smoking. In the male subgroup, $8.1 \%$ were non-smokers, $70.6 \%$ were exsmokers, and $21.3 \%$ were active smokers. In the female subgroup, $70 \%$ were non-smokers, $17.7 \%$ were ex-smokers, and $12.3 \%$ were active smokers. Table 1 shows the sociodemographic characteristics of the study population according to gender and smoking habit.

The mean $\mathrm{FEV}_{1}$ was $57.4 \pm 13.4 \%$. The degree of airways obstruction was significantly greater in men than in women $(56.64 \pm 13.35 \%$ vs $60.72 \pm 13.26 \%$, p < 0.05$)$. As regards comorbidity, the women showed a higher frequency of hypertension $(49.5 \%$ vs $47.1 \%$ in men, p < $0.05)$, diabetes mellitus ( $18.4 \%$ vs $16.4 \%$, $\mathrm{p}<0.05)$, anxiety $(36.7 \%$ vs $17.6 \%$, p < 0.05$)$, depression $(23.1 \%$ vs $9.5 \%, \mathrm{p}<0.05)$ and allergy $(13.2 \%$ vs $5.7 \%, \mathrm{p}<0.05)$. In

Table I: Sociodemographic characteristics of the studied COPD patients, according to gender and smoking habit.

\begin{tabular}{|c|c|c|c|c|}
\hline VARIABLE & Male non-smokers & Male smokers & Female non-smokers & Female smokers \\
\hline Age $($ mean $\pm S D)+\dagger$ & (647) $66.99 \pm 10.06$ & (7356) $67.47 \pm 9.13$ & $(I 803) 68.58 \pm 10.08$ & (773) $60.21 \pm 10.26$ \\
\hline \multicolumn{5}{|l|}{ Occupational status: } \\
\hline - Inactive (\%) & (440) 73.9 & (5184) 77.6 & (1417) 84.7 & (428) 58.9 \\
\hline - Active $(\%)+\dagger$ & (I55) 26.0 & (1494) 22.4 & $(256) 15.3$ & (298) 41.0 \\
\hline \multicolumn{5}{|l|}{ Educational level: } \\
\hline - Patients without basic schooling (\%) & (77) 14.7 & (I I42) 18.3 & (536) 35.4 & (85) 13.2 \\
\hline - Primary (\%) & (308) 58.7 & (3630) 58.1 & $(8 \mid 2) 53.7$ & (304) 47.1 \\
\hline - Secondary (\%) & (103) 19.6 & (II5I) 18.4 & (138) 9.1 & (I78) 27.6 \\
\hline - University $(\%)+\dagger$ & (37) 7.0 & (326) 5.2 & (27) 1.8 & (79) 12.2 \\
\hline
\end{tabular}

* Significant difference in the comparison of male smokers versus male non-smokers.

+ Significant difference in the comparison of female smokers versus female non-smokers.

† Significant difference in the comparison of male smokers versus female smokers.

Significant difference in the comparison of male non-smokers versus female non-smokers. 
contrast, males showed a comparatively higher frequency of heart disease $(19.6 \%$ vs $16.3 \%$ in women, $\mathrm{p}<0.05)$ and peptic ulcer $(18.8 \%$ vs $12.7 \%, \mathrm{p}<0.05)$. As to healthrelated quality of life, after adjusting by age and severity, there were no significant gender differences in the scores corresponding to the physical component $(35.96 \pm 9.94$ in men vs $35.91 \pm 9.91$ in women), though the gender differences were significant in the case of the mental component ( $49.41 \pm 10.33$ in men vs $44.66 \pm 11.97$ in women). Table 2 reports the health profile, the severity of airways obstruction, comorbidity, and quality of life of the studied COPD patients, according to gender and smoking.

The men received a larger number of drugs for COPD than the women. Thus, men used an average of $2.32 \pm 1.03$ drugs, compared with $2.17 \pm 1.04$ in the case of the women - the difference being statistically significant. Likewise significantly greater among males was the percentage use of long-acting $\mathrm{b}_{2}$-adrenergic agonists $(9.8 \%$ vs $7.9 \%$ in females, $\mathrm{p}<0.05)$, anticholinergic drugs $(85.6 \%$ vs $82.4 \%, \mathrm{p}<0.05)$, theophyllines $(13.2 \%$ vs $7.6 \%$, p < $0.05)$ and mucolytic agents $(9.3 \%$ vs $7.7 \%, \mathrm{p}<0.05)$.
However, no gender differences were recorded in the frequency of administration of corticoids - both inhalatory (22.1\% in males vs $22.2 \%$ in females) and oral (4.4\% vs $5.3 \%)$. As to vaccination antecedents, men received the antiinfluenza vaccine during the last campaign more often than women $(88.1 \%$ vs $84.7 \%$, p < 0.05). Table 3 reports the drug treatment and vaccinations of the study population according to gender and smoking habit.

Utilization of ressources in the last year was greater among male smokers than in male non-smokers. Differences were also detected in the number of primary care visits between male and female smokers (Table 4).

The total annual cost of COPD management per patient was greater in males than in females $(1989.20 \pm 2364.47$ vs $1724.53 \pm 2106.90, \mathrm{p}<0.05)$. Differences were likewise detected between male smokers and female smokers $(2023.29 \pm 2384.22$ vs $1696.15 \pm 2165.94, \mathrm{p}<0.05)$. Table 5 shows the cost of the different health care resources utilized by the COPD patients according to gender and smoking habit.

Table 2: Health profile, severity of airways obstruction according to FEV , co-morbidity, and quality of life (generic SF- 12 questionnaire) of the studied COPD patients, according to gender and smoking habit.

\begin{tabular}{|c|c|c|c|c|}
\hline Parameter & Male non-smokers & Male smokers & Female non-smokers & Female smokers \\
\hline \multicolumn{5}{|l|}{ Physical exercise: $* \dagger$} \\
\hline - None (\%) & (153) 21.9 & (2233) 30.6 & (758) 42.5 & (232) 30.4 \\
\hline - Light (\%) & (436) 68.1 & (4735) 64.8 & (98I) 55.0 & (474) 62.0 \\
\hline - Moderate (\%) & (5I) 8.0 & (334) 4.6 & (43) 2.4 & (58) 7.6 \\
\hline \multicolumn{5}{|l|}{ Obesity: $+\dagger$} \\
\hline - Normal weight (\%) & (130) 20.6 & (1616) 22.3 & (445) 25.6 & (279) 36.6 \\
\hline - Overweight (\%) & (382) 60.6 & 57.0 & (786) 45.2 & (342) 44.8 \\
\hline - Obese (\%) & (1 18$) 18.7$ & (I489) 20.6 & (509) 29.2 & (142) 18.6 \\
\hline \multicolumn{5}{|l|}{ Severity of obstruction (according to FEVI) $*+\dagger$} \\
\hline Mild & (270) 44.1 & (2276) 32.2 & (695) 40.7 & (342) 46.4 \\
\hline Moderate & (296) 48.4 & (3906) 55.2 & (86I) 50.5 & 47.9 \\
\hline Severe & (46) 7.5 & $(896) 12.7$ & $(150) 8.8$ & (42) 5.7 \\
\hline \multicolumn{5}{|l|}{ Comorbidity: } \\
\hline - Hypertension $(\%) *+\dagger$ & (229) 40.0 & (3259) 47.8 & (899) 53.8 & (277) 39.3 \\
\hline - Hypercholesterolemia (\%) * & (197) 35.2 & (2833) 42.3 & (668) 41.0 & 38.0 \\
\hline - Heart disease $(\%)+\dagger$ & (84) 15.4 & (1294) 19.9 & $(301) 18.9$ & (65) 9.8 \\
\hline - Gastroduodenal ulcer (\%) $* \dagger$ & (75) 13.7 & (1254) 19.2 & (207) 13.1 & (78) 11.7 \\
\hline - Depression (\%) † & (46) 8.5 & $(619) 9.6$ & (353) 22.2 & (I68) 25.2 \\
\hline - Anxiety $(\%) \dagger$ & (89) 16.2 & (II45) 17.7 & (568) 35.6 & (264) 39.4 \\
\hline - Diabetes(\%)+ & (7I) 13.0 & (1089) 16.7 & (322) 20.1 & (96) 14.4 \\
\hline SFI 2 mental component (mean \pm SD) $\dagger$ & (647) $50.3 \pm 9.8$ & (7356) $49.3 \pm 10.4$ & (1803) $44.5 \pm 12.0$ & $4773 \pm 12.1$ \\
\hline $\mathrm{SFI} 2$ physical component (mean $\pm \mathrm{SD}) *+\dagger$ & $(647) 38.1 \pm 10.0$ & (7356) $35.8 \pm 9.9$ & $(1803) 34.6 \pm 9.6$ & (773) $38.9 \pm 9.8$ \\
\hline
\end{tabular}

Normal weight (BMI < 27), Overweight (BMI $\geq 27<30)$, Obesity (BMI $\geq 30$ ).

* Significant difference in the comparison of male smokers versus male non-smokers.

+ Significant difference in the comparison of female smokers versus female non-smokers.

† Significant difference in the comparison of male smokers versus female smokers, after adjusting by age and severity

Significant difference in the comparison of male non-smokers versus female non-smokers, after adjusting by age and severity. 
Table 3: Drug treatment and vaccinations of the studied COPD patients, according to gender and smoking habit.

\begin{tabular}{|c|c|c|c|c|}
\hline Treatment & Male non-smokers & Male smokers & Female non-smokers & Female smokers \\
\hline Short-acting $\beta 2$-adrenergic agonists (\%)* & (216) 33.4 & (2927) 39.8 & (685) 38.0 & (289) 37.4 \\
\hline Long-acting $\beta 2$-adrenergic agonists (\%) & (53) 8.2 & (735) 10.0 & (I49) 8.3 & $(55) 7.1$ \\
\hline Anticholinergic agents $(\%) \dagger$ & (549) 84.8 & (6304) 85.7 & (1489) 82.6 & (635) 82.1 \\
\hline Theophyllines (\%)† & (64) 9.9 & $(986) \quad 13.4$ & (155) 8.6 & (42) 5.4 \\
\hline Inhalatory corticoids (\%)+† & (123) 19.0 & (1648) 22.4 & (44I) 24.4 & (130) 16.8 \\
\hline Oral corticoids (\%) & (27) 4.2 & (33I) 4.5 & $(105) 5.8$ & (3I) 4.0 \\
\hline Mucolytic agents $(\%) \dagger$ & (50) 7.7 & (692) 9.4 & (I5I) 8.4 & (48) 6.2 \\
\hline Antiinfluenza vaccine in last campaign $(\%)+\dagger$ & (547) 85.3 & (6409) 88.3 & (1585) 88.9 & (568) 74.8 \\
\hline Antipneumococcal vaccination at some time in past $(\%)+\dagger$ & $(210) 33.5$ & (2332) 32.8 & $(618) 35.5$ & (I50) 20.2 \\
\hline
\end{tabular}

* Significant difference in the comparison of male smokers versus male non-smokers.

+ Significant difference in the comparison of female smokers versus female non-smokers.

† Significant difference in the comparison of male smokers versus female smokers, after adjusting by age and severity

Significant difference in the comparison of male non-smokers versus female non-smokers, after adjusting by age and severity.

\section{Discussion}

The main finding of this study is that there are differences in the sociodemographic characteristics, associated diseases, quality of life, treatment, utilization of resources and cost of COPD according to patient gender and smoking habit. The true strength of the survey is found in the large number of patients involved, and in the fact that these were real-life subjects not included in a clinical trial but recruited in the primary care setting.

A number of previous studies have reported gender differences in the clinical presentation, diagnosis, treatment and prognosis of COPD [15-20]. Thus, it has been shown that women have more respiratory symptoms than men, with increased airways responsiveness, lower quality of life questionnaire scores, lesser response to prolonged treatment with exercise, and a more favorable prognosis at the time of starting oxygen therapy.

Of note in the present study is the large proportion of non-smoking women. No evaluation has been made of passive exposure to tobacco smoke, though women are known to be more exposed, and are more sensitive to exposure, than men [21]. In any case, earlier studies have shown the implication of other risk factors in the pathogenesis of COPD, including genetic factors, infections, environmental pollution, and occupational exposure [22]. Thus, as an example, a recent study has demonstrated a relationship between exposure to the smoke of burning wood or coal and the development of COPD [23]. The fact that our patients had been diagnosed with COPD for one year and presented spirometric evidence of airways obstruction upon inclusion in the study, increases the reliability of our findings. Another possibility is that a proportion of the non-smoking women in our series may actually not have COPD but other disorders characterized by airways obstruction, such as asthma. In fact, the percentage of an allergy history was higher in the female group. In this sense, no bronchodilator tests were carried out in this study, though it has been shown that unless full obstruction reversion is achieved, the mentioned test shows poor performance in discriminating between COPD and asthma [24]. In any case, the balance of error tends to tip in the opposite direction, i.e., it is more common to diagnose women with respiratory symptoms of asthma than of COPD $[20,25]$, in the same way as among non-smokers [26]. On the other hand, and as has been commented above, in the evaluation of the clinical course, the subjects with asthma features were excluded; as a result, the impact of asthma upon the end results is scantly relevant.

Table 4: Utilization of health care resources in the previous year among the COPD patients according to gender and smoking habit.

\begin{tabular}{lcccc}
\hline Health care resources & Male non-smokers & Male smokers & Female non-smokers & Female smokers \\
\hline No. visits to primary care $* \dagger$ & $(625) 5.91 \pm 5.67$ & $(7045) 6.77 \pm 5.75$ & $(1724) 6.69 \pm 5.72$ & $(731) 6.18 \pm 5.30$ \\
No. visits to pneumology clinic $*$ & $(602) 1.30 \pm 1.53$ & $(6838) 1.47 \pm 1.54$ & $(1640) 1.37 \pm 1.40$ & $(706) 1.32 \pm 1.59$ \\
No. visits to emergency service $*$ & $(581) 1.70 \pm 0.81$ & $(6608) 1.90 \pm 0.87$ & $(1592) 1.84 \pm 0.86$ & $(684) 1.84 \pm 0.89$ \\
No. hospital admissions $*$ & $(523) 0.36 \pm 0.83$ & $(6026) 0.54 \pm 1.27$ & $(1429) 0.44 \pm 0.93$ & $(598) 0.41 \pm 0.94$ \\
Duration hospital stay (days)* & $(262) 5.74 \pm 10.49$ & $(3325) 7.67 \pm 11.54$ & $(773) 6.26 \pm 10.37$ & $(335) 6.27 \pm 14.00$ \\
\hline
\end{tabular}

* Significant difference in the comparison of male smokers versus male non-smokers.

+ Significant difference in the comparison of female smokers versus female non-smokers.

$\dagger$ Significant difference in the comparison of male smokers versus female smokers, after adjusting by age and severity.

Significant difference in the comparison of male non-smokers versus female non-smokers, after adjusting by age and severity. 
Table 5: Cost of health care resources utilized among the COPD patients according to gender and smoking habit.

\begin{tabular}{|c|c|c|c|c|}
\hline Cost component & Male non-smokers & Male smokers & Female non-smokers & Female smokers \\
\hline Visits to primary care physician $(€) * \dagger$ & (647) $95.77 \pm 95.17$ & (7356) $108.81 \pm 97.16$ & (1803) $107.25 \pm 96.68$ & (773) $97.92 \pm 89.58$ \\
\hline Visits to pneumologist $(€) \dagger$ & $(647) 85.35 \pm 107.16$ & (7356) $96.44 \pm 108.63$ & (I803) $88.01 \pm 98.77$ & (773) $85.21 \pm 110.45$ \\
\hline Visits to emergency service $(€) *$ & (647) $101.45 \pm 158.97$ & (7356) $139.67 \pm 199.43$ & (I803) $125.73 \pm 179.95$ & (773) $129.12 \pm 209.41$ \\
\hline Hospital admission $(€) * \dagger$ & (647) $584.04 \pm 1532.18$ & (7356) $849.24 \pm 1827.62$ & (1803) $685.60 \pm 1598.17$ & (773) $642.26 \pm 1702.83$ \\
\hline Diagnostic tests $(€) \dagger$ & (647) $117.77 \pm 147.87$ & (7356) $133.08 \pm 149.89$ & $(1803) 121.44 \pm 136.29$ & (773) $|17.58 \pm 152.4|$ \\
\hline Respiratory drugs $(€) \dagger$ & (647) $47 \mathrm{I} .97 \pm 40 \mathrm{I} .2 \mathrm{I}$ & (7356) $502.24 \pm 415.07$ & (I803) $477.62 \pm 409.10$ & (773) $443.92 \pm 387.19$ \\
\hline Oxygen therapy $(€) * \dagger$ & $(647) 54.72 \pm 223.56$ & (7356) $105.88 \pm 312.46$ & (1803) $77.00 \pm 271.35$ & (773) $48,93 \pm 219.68$ \\
\hline Sick leave $(€)+\dagger$ & (647) $56.81 \pm 280.13$ & (7356) $70.16 \pm 291.70$ & (I803) $35.39 \pm 205.88$ & (773) $118.63 \pm 339.38$ \\
\hline Antiinfluenza vaccination $(€)+\dagger$ & (647) $0.18 \pm 0.55$ & (7356) $0.20 \pm 0.58$ & (1803) $0.17 \pm 0.54$ & (773) $0.37 \pm 0.75$ \\
\hline Antipneumococcal vaccination $(€)+\dagger$ & (647) $4.76 \pm 6.87$ & (7356) $4.65 \pm 6.83$ & (I803) $5.03 \pm 6.96$ & (773) $2.84 \pm 5.80$ \\
\hline Total annual cost per COPD patient $(€) * \dagger$ & $(647) 1585.93 \pm 2085.04$ & (7356) $2023.29 \pm 2384.22$ & (I803) $1736.78 \pm 2078.85$ & (773) $1696.15 \pm 2165.94$ \\
\hline
\end{tabular}

* Significant difference in the comparison of male smokers versus male non-smokers.

+ Significant difference in the comparison of female smokers versus female non-smokers.

† Significant difference in the comparison of male smokers versus female smokers, after adjusting by age and severity.

Significant difference in the comparison of male non-smokers versus female non-smokers, after adjusting by age and severity.

Some studies suggest that women are more susceptible to the deleterious effects of smoking. A number of publications suggest that women have lung function similar to that of males at a younger age and with a lesser smoking history [9,27-32]. Gender-associated differences have also been found in the gradual worsening of lung function in smokers with COPD [33]. Thus, the annual decline in lung function in women has been associated with the degree of airways obstruction - an effect not seen in males.

Some authors report that women have fewer associated diseases than males with the same degree of airways obstruction [9]. In this study it has been shown that in general hypertension and diabetes mellitus is more common in women, while men show a larger proportion of other disorders such as hypercholesterolemia and ischemic heart disease - with differences in both cases according to smoking status. In addition, anxiety and depression were more frequent in women. Di Marco et al. also observed that women with COPD appear to be more exposed to psychological problems - these being related to symptomatic aspects of the disease such as dyspnea [34]. Lastly, and in coincidence with earlier studies reporting gender-associated differences in atopic markers [3537], we recorded an increased allergy history in women compared with men. Other authors have published similar results [38,39].

As regards treatment, earlier studies have reported an increased frequency of inhalatory corticoid use among women, with a comparatively lower percentage use of theophyllines [40]. We likewise observed a lesser percentage use of theophyllines among women than in men - possibly in relation to the lesser severity of airways obstruction among the former. In relation to oxygen therapy, it has been shown that the mortality risk among COPD patients administered such therapy is greater in women than in men [41]. An explanation for such a poorer prognosis among women could be that the systemic complications of COPD, such as muscle dysfunction or depression, are more frequent in women and involve a poorer patient course [42].

Gender-associated differences were also observed in utilization of health resources. In fact, women have been shown to make more frequent utilization of health care services than men [43]. It also has been suggested that the risk for hospital admission is greater among women, and that the number of admissions due to COPD will gradually increase among females in the coming years $[43,44]$. In our study, gender differences were seen in the frequency of visits to the primary care physician - with more frequent visits among male smokers than in female smokers - and in the number of visits to the emergency service (greater in non-smoking women than in non-smoking men).

As refers to health-related quality of life, some authors have found that, for one same FEV1 level, women yield poorer scores in all domains of the St. George questionnaire [9]. In addition, the factors associated to quality of life have been shown to vary between sexes. Thus, in males, the main predictors include dyspnea, exercise capacity, the degree of hyper-insufflation, and comorbidity - while in women the main predictors are dyspnea and arterial oxygenation [45]. Other studies have reported poorer scores in the quality of life questionnaires in women compared with men [16-34,46-49]. In our study, women yielded lower scores in the mental component of quality of life, but not in the physical dimension. However, gender differences were obtained in this parameter according to patient smoker status. As regards the financial factors, we found the costs associated with COPD to be generally higher in males - particularly among the smokers. In contrast, other studies have reported no gen- 
der-associated differences in the costs associated with this disease [50]. These results should be taken into account when designing specific treatment strategies for different groups of COPD patients.

A possible limitation of our study is that, as commented previously in the method section, we did not use logistic regression with random effects. Ignoring clustering and unequal probability of selection of participants in our analyses may result in biased estimates [51,52].

\section{Conclusion}

In conclusion, there are gender-related differences in the clinical characteristics, management, quality of life, and costs of COPD. The women with COPD evaluated in this study were younger, smoked less and have more comorbidity, a poorer quality of life and lesser disease severity than men with COPD. In addition, they used fewer drugs and health care resources than males - though there were also differences between the two gender groups according to smoker status.

\section{Competing interests}

JRG and AMC are employees at Pfizer Spain and EGV is employee at Boehringer Ingelheim SA. The other authors have not any conflict of interest with Pfizer or Boehringer Ingelheim SA. This study has been funded by an unrestricted grant from Pfizer Spain and Boehringer Ingelheim SA.

\section{Authors' contributions}

PCG, JRG, VHB, AGM and RJG have made substantive intellectual contributions to conception and design, acquisition of data and analysis and interpretation of data. PCG, JRG, JMD, AMC, AGM, and EGV have been envolved in drafting the manuscript and revising it critically for important intellectual content. All authors have given final approval of the version to be published.

\section{Acknowledgements}

To all patients and primary care physicians who have voluntarily collaborated in the EPIDEPOC study. This study has been financed by Pfizer SA and Boehringer Ingelheim SA through contract No. A040 signed with the University Rey Juan Carlos of Madrid.

\section{References}

I. Soriano JB, Maier WC, Egger P, Visick G, Thakrar B, Sykes J, Pride NB: Recent trends in physician diagnosed COPD in women and men in the UK. Thorax 2000, 55:789-794.

2. Ulrik CS: Smoking and mortality in women: "smoke like a man, die (at least) like a man". Respiratory Disease in Women. Eur Respir Mon 2003, 25:103-117.

3. Mannino DM, Homa DM, Akinbami LJ, Ford ES, Redd SC: Chronic obstructive pulmonary disease surveillance-United States, 197|-2000. MMWR Surveill Summ 2002, 5 I(6): I- 16.

4. Lacasse $Y$, Brooks D, Goldstein RS: Trends in the epidemiology of COPD in Canada, 1980 to 1995. COPD and rehabilitation committee of the Canadian Thoracic Society. Chest 1999, I | 6:306-3|3.
5. Keistinen T, Vilkman S, Tuuponen T, Kivela SL: Hospital admissions for chronic obstructive pulmonary disease in the population aged 55 years or over in Finland during 1972-1992. Public Health 1996, I I 0:257-259.

6. Chapman KR, Tashkin DP, Pye DJ: Gender bias in the diagnosis of COPD. Chest 200I, I 19:169I-1695.

7. Varkey $A B$ : Chronic obstructive pulmonary disease in women: exploring gender differences. Curr Opin in Pulm Med 2004, 10:98-103.

8. Han MK, Postma D, Mannino DM, Giardino ND, Buist S, Curtis JL, Martínez FJ: Gender and chronic obstructive pulmonary disease: why it matters. Am 」 Respir Crit Care Med 2007, 176: I I79-II84

9. de Torres JP, Casanova C, Hernández C, Abreu J, Aguirre-Jaime A, Celli BR: Gender and COPD in patients attending a pulmonary clinic. Chest 2005, I 28:2012-2016.

10. Leynaert B, Bousquet J, Henry C, Liard R, Neukirch F: Is bronchial responsiveness more frequent in women than in men?. A population based study. Am J Respir Crit Care Med 1997, 156:1413-1420.

II. Carrasco Garrido P, de Miguel Díez J, Rejas Gutiérrez J, Martín Centeno A, Gobartt Vázquez E, Gil de Miguel A, García Carballo M, Jiménez García R: Negative impact of chronic obstructive pulmonary disease on the health-related quality of life of patients. Results of the EPIDEPOC study. Health Qual Life Outcomes 2006, 4:31.

12. Barberà JA, Peces-Barba G, Agustí AGN, lzquierdo JL, Monsó E, Montemayor T, Viejo JL: Guía clínica para el diagnóstico y el tratamiento de la enfermedad pulmonar obstructiva crónica. Arch Bronconeumol 200I, 37:297-316.

13. Ware JE, Kosinski M, Keller SD: A I 2-item short-form health survey. Construction of scales and preliminary tests of realiabity and validity. Med Care 1996, 34:220-233.

14. Instituto Nacional de Estadística [http://www.ine.es.]

15. Foy CG, Rejeski WJ, Berry MJ, Zaccaro D, Woodard CM: Gender moderates the effects of exercise therapy on health-related quality of life among COPD patients. Chest 200I, I I 9:70-76.

16. Larson J, Kirchgessner J, McCutcheon J: Quality of life in chronic obstructive pulmonary disease: gender differences. $A m J$ Respir Crit Care Med 1998, I57:A869.

17. Kanner RE, Connet JE, Altose MD, Buist AS, Lee WW, Tashkin DP, Wise RA: Gender difference in airway hyperresponsiveness in smokers with mild COPD. The Lung Health Study. Am J Respir Crit Care Med 1994, 150:956-96I.

18. PAARC: Group Coopératif. Pollution atmosphérique et affections respiratoires chroniques ou á répétition. Bull Eur Physiopathol Respir 1982, 18:87-99.

19. Miyamoto K, Aida A, Nishimura M, Aiba M, Kira S, Kawakami Y: Gender effects on prognosis of patients receiving long term home oxygen therapy. The Respiratory Failure Research Group in Japan. Am J Respir Crit Care Med 1995, I 52:972-975.

20. Dales RE, Mehdizadeh A, Aaron SD, Vandemheen KL, Clinch J: Sex differences in the clinical presentation and management of airflow obstruction. Eur Respir J 2006, 28:319-322.

21. Kauffmann F, Becklake MR: Sex and gender. Respiratory epidemiology in Europe. Eur Respir Mon 2000, 5:288-304.

22. Varkey $A B$ : Chronic obstructive pulmonary disease in women: exploring gender differences. Curr Opin Pulm Med 2004, 10:98-103.

23. Orozco-Levi M, Garcia-Aymerich J, Villar J, Ramirez-Sarmiento A, Anto JM, Gea J: Wood smoke exposure and risk of chronic obstructive pulmonary disease. Eur Respir J 2006, 27:542-546.

24. de Miguel Díez J, Izquierdo Alonso JL, Molina París J, Rodríguez González-Moro JM, de Lucas Ramos P, Gaspar Alonso-Vega G: Fiabilidad del diagnóstico de la EPOC en atención primaria y neumología en España. Factores predictivos. Arch Bronconeu$\mathrm{mol}$ 2003, 39:203-208.

25. Chapman KR, Tashkin DP, Pye DJ: Gender bias in the diagnosis of COPD. Chest 2001, I 19:1691-1695.

26. Bleecker ER: Similarities and differences in asthma and COPD: the Dutch hypothesis. Chest 2004, I 26(Suppl):93S-95S.

27. O'Donnell D, Aaron SD, Bourbeau J, Hernandez P, Marciniuk D, Balter M: Canadian Thoracic Society recommendations for management of chronic obstructive pulmonary disease2003. Can Respir J 2003, I O(suppl A): I IA-33A. 
28. Lemière $C$, Bai $T$, Balter $M$, Bayliff $C$, Becker $A$, Boulet LP, Bowie $D$, Cartier A, Cave A, Chapman K, Cowie R, Coyle S, Cockcroft D, Ducharme FM, Ernst P, Finlayson S, FitzGerald JM, Hargreave FE, Hogg D, Kaplan A, Kim H, Kelm C, O'Byrne P, Sears M, Markham AW: Adult asthma consensus guidelines update 2003. Can Respir J 2004, I I(Suppl A):9A- I8A.

29. Lethbridge-Cejku M, Schiller JS, Bernadel L: Summary health statistics for U.S. adults: National Health Interview Survey, 2002. Vital Health Stat 10 2004, 222:I-I5I.

30. Chen Y, Horne SL, Dosman JA: Increased susceptiblity to lung dysfunction in female smokers. Am Rev Respir Dis 1991, 143: 1224-1230.

31. Samet JM, Lange P: Longitudinal studies of active and passive smoking. Am J Respir Crit Care Med 1996, I 54(6 Pt 2):S257-S265.

32. $X u X, L i B$, Wang $L$ : Gender difference in smoking effects on adult pulmonary function. Eur Respir J 1994, 7:477-483.

33. Watson L, Vonk JM, Löfdahl CG, Pride NB, Pauwels RA, Laitinen LA, Schouten JP, Postma DS: European Respiratory Society study on chronic obstructive pulmonary disease. Predictors of lung function and its decline in mild to moderate COPD in association with gender: results from the Euroscop study. Respir Med 2006, 100:746-753.

34. Di Marco F, Verga M, Reggente M, Casanova FM, Santus P, Blasi F, Allegra L, Centanni S: Anxiety and depression in COPD patients: the roles of gender and disease severity. Respir Med 2006, 100: 1767-1774.

35. Lebowitz MD, Knudson RJ, Burrows B: Tucson epidemiologic study of obstructive lung diseases: methodology and prevalence of disease. Am J Epidemiol 1975, 102:137-152.

36. Barbee RA, Kaltenborn W, Lebowitz MD, Burrows B: Longitudinal changes in allergens skin test reactivity in a community population sample. J Allergy Clin Immunol 1987, 79:16-24.

37. Cline MG, Burrows $B$ : Distribution of allergy in a population sample residing in Tucson, Arizona. Thorax 1989, 44:425-431.

38. Chavannes NH, Huibers MJ, Schermer TR, Hendriks A, van Weel C, Wouters EF, van Schayck CP: Associations of depressive symptoms with gender, body mass index and dyspnea in primary care COPD patients. Fam Pract 2005, 22:604-607.

39. Andrade L, Caraveo-Anduaga JJ, Berglund P, Bijl RV, De Graaf R, Vollebergh W, Dragomirecka E, Kohn R, Keller M, Kessler RC, Kawakami N, Kiliç C, Offord D, Ustun TB, Wittchen HU: The epidemiology of major depressive episodes: results from the International Consortium of Psychiatric Epidemiology (ICPE) Surveys. Int J Methods Psychiatr Res 2003, I 2:3-21.

40. de Miguel Díez J, Izquierdo Alonso JL, de Lucas Ramos P, Rodríguez González-Moro JM, Bellón Cano JM, Molina París J: Expresión clínica de la EPOC. ¿Existen diferencias según el sexo? Rev Patol Respir 2003, 6: 162-166.

4I. Machado MC, Krishnan JA, Buist SA, Bilderback AL, Fazolo GP, Santarosa MG, Queiroga F Jr, Vollmer WM: Sex differences in survival in oxygen-dependent patients with chronic obstructive pulmonary disease. Am J Respir Crit Care Med 2006, 174:524-529.

42. Mannino DM: Women and chronic obstructive pulmonary disease. Does Sex Influence Survival? Am J Respir Crit Care Mes 2006, 174:488-489.

43. Prescott E, Bjerg AM, Andersen PK, Lange P, Vestbo J: Gender difference in smoking effects on lung function and risk of hospitalization for COPD: results from a Danish longitudinal population study. Eur Respir J 1997, 10:822-827.

44. Chan-Yeung M, Ait-Khaled N, White N, Ip MS, Tan WC: The burden and impact of COPD in Asia and Africa. Int J Tuberc Lung Dis 2004, 8:2-14.

45. Katsura H, Yamada K, Wakabayashi R, Kida K: Gender-associated differences in dyspnoea and health-related quality of life in patients with chronic obstructive pulmonary disease. Respirology 2007, 1 2:427-432.

46. de Torres JP, Casanova C. Hernandez C, Abreu J, Montejo de Garcini A, Aguirre-Jaime A, Celli BR: Gender associated differences in determinants of quality of life in patients with COPD: a case series study. Health Qual Life Outcomes 2006, 4:72.

47. Osman LM, Godden DJ, Friend JAR, Legge JS, Douglas JG: Quality of life and hospital re-admission in patients with chronic obstructive pulmonary disease. Thorax 1997, 52:67-71.

48. Leidy NK, Traver G: Psychophysiologic factors contributing to functional performance in people with COPD: are there gender differences? Res Nurs Health 1995, 18:535-546.
49. Rodrigue JR, Baz MA: Are there sex differences in the healthrealated quality of life after lung transplantation for chronic obstructive pulmonary disease? J Heart Lung Transplant 2006, 25:120-125.

50. Baldea L, Svenninga AD, Dollerupb J, Borgeskovc HB, Langed P: The cost of treating patients with COPD in Denmark - A population study of COPD patients compared with non-COPD controls. Respir Med 2007, 101:539-546.

5I. Larsen K, Petersen JH, Budtz-Jørgensen E, Endahl L: Interpreting parameters in the logistic regression model with random effects. Biometrics 2000, 56:909-9|4.

52. Sampling of populations: methods and applications. Edited by: Paul S. Levy, Stanley Lemeshow. John Wiley and Sons; 1999.

\section{Pre-publication history}

The pre-publication history for this paper can be accessed here:

http://www.biomedcentral.com/1471-2466/9/2/prepub
Publish with Bio Med Central and every scientist can read your work free of charge

"BioMed Central will be the most significant development for disseminating the results of biomedical research in our lifetime. "

Sir Paul Nurse, Cancer Research UK

Your research papers will be:

- available free of charge to the entire biomedical community

- peer reviewed and published immediately upon acceptance

- cited in PubMed and archived on PubMed Central

- yours - you keep the copyright

Submit your manuscript here:

http://www.biomedcentral.com/info/publishing_adv.asp
BioMedcentral 